\title{
Depression Among HIV/AIDS Patients on Highly Active Antiretroviral Therapy in the Southwest Regional Hospitals of Cameroon: A Cross-Sectional Study
}

Pleasure Atoh Ngum • Peter Nde Fon • Roland Cheofor Ngu •

Vincent Siysi Verla $\cdot$ Henri Namme Luma

Received: January 14, 2017 / Published online: March 18, 2017

(c) The Author(s) 2017. This article is an open access publication

\begin{abstract}
Introduction: HIV patients are now having longer life expectancies with the use of antiretroviral therapy (ART). However, the issue of mental illness has surfaced with depression being the most common in these patients, which has markedly reduced patient adherence to ART. In Cameroon, the management of HIV/ AIDS does not incorporate psychiatric manifestations and depression is therefore underdiagnosed. The aim of our study was to determine
\end{abstract}

Enhanced content To view enhanced content for this article go to http://www.medengine.com/Redeem/ D4F7F0600BA97D20.

P. A. Ngum - P. N. Fon - V. S. Verla · H. N. Luma Faculty of Health Sciences, University of Buea, Buea, Cameroon

R. C. Ngu ( $\square)$

Mboppi Baptist Hospital Douala, Douala, Cameroon e-mail: rolinaro@gmail.com

R. C. Ngu

Human Health and Disease Connection (2HD)

Research Group, Douala, Cameroon

R. C. Ngu

Medical Doctors (MD) Research Group, Douala, Cameroon

H. N. Luma

Douala General Hospital, Douala, Cameroon the prevalence and determinants of depressive symptoms and their association with adherence to ART among HIV/AIDS patients on HAART in the Southwest Regional Hospitals of Cameroon. Methods: This was a cross-sectional hospital-based study carried out in the BRH and LRH over a 3-month period. Three hundred HIV patients aged 21 and above were recruited. Depression and adherence to treatment were assessed using the nine-item Patient Health Questionnaire (PHQ-9) and eight-item Morisky Medication Adherence Scale questionnaires, respectively. Data were analysed using Epi-info version 3.4.5.

Results: The prevalence of depression was $26.7 \%$ (95\% CI 20.6-33.7\%); $75.0 \%$ of those with depression were non-adherent to HAART compared to $37.3 \%$ of those without depression ( $p$ value $<0.001)$. The statistically significant risk factors associated with depression were unemployment (OR 2.38; 95\% CI 1.26-4.50), age $\leq 40$ years (OR 2.13; 95\% CI 1.20-3.70) and CD4 counts $\leq 200$ cells $/ \mu \mathrm{l} \quad(\mathrm{OR} \quad 3.70 ; \quad 95 \% \quad \mathrm{CI}$ 1.45-9.09).

Conclusion: The prevalence of depression was high and depression was significantly associated with non-adherence to HAART. Interventions to enhance early identification and treatment of depression in patients with HIV/AIDS are needed. Depression screening should be included as part of the routine consultation of HIV/AIDS patients to ensure early detection and treatment. 
Keywords: Adherence;

Determinants; HAART

\section{INTRODUCTION}

HIV/AIDS is a major cause of disability and death, particularly in low- and middle-income nations [1]. The first cases were reported in 1981 and from the beginning of the pandemic more than 3 decades ago to the end of 2015, about 35 million (29.6-40.8 million) people have died of HIV/AIDS-related illnesses [2] with Sub-Saharan Africa being the most affected, accounting for $74 \%$ of AIDS-related deaths worldwide in 2013 [3]. Nearly 30 years after its discovery, HIV infection remains the number one cause of disease-related mortality in Sub-Saharan Africa [4]. Globally, 36.7 million (34.0-39.8 million) people were living with HIV(PLWH) at the end of 2015 with approximately 70\% residing in Sub-Saharan Africa [5], an area with only approximately $12 \%$ of the world's population. Sub-Saharan Africa also accounted for 410,000 cases of new HIV infection in 2015 [6]. Recent estimates set the prevalence of HIV/AIDS in Cameroon to be $4.46 \%$ in adults aged 15-49 years as of 2015 [7].

Mental health and HIV/AIDS are closely interlinked. Mental health problems are associated with an increased risk of HIV/AIDS infection and interfere with the treatment; conversely some mental disorders occur as a direct result of HIV infection [1]. Depression contributes significantly to disease morbidity and affects people in all communities across the globe. Depression nowadays is estimated to affect 350 million people [8]. It is well known that major depressive disorder (MDD) is the most common prevalent neuropsychiatric symptom in HIV-1 patients [9]. Depression and HIV/AIDS are forecasted to be the world's two leading causes of disability by 2030 [10]. Research has shown those individuals who are infected with HIV are more likely to develop depression than the general population. Depression affects an individual's ability to comply with HIV/AIDS treatment, as well as quality of life and lifespan [11]. Depression may seem like an inevitable reaction to being diagnosed with HIV/AIDS; however it is a separate illness that can and should be treated, even when a person is on antiretrovirals [12]. Depression is a distressing and impairing condition that has detrimental effects on many of the self-care behaviours necessary for optimal management of HIV [13]. For instance, patients with depression tend to initiate ART at higher HIV-1 RNA levels and at lower CD4 cell counts compared to their non-depressed counterparts [14]. In addition, depression has been closely connected to poor adherence to ART once initiated [15].

Data on the prevalence of depression in HIV-infected patients are conflicting. A study carried out in South Africa gave the prevalence of depression in HIV patients as 42.4\% [16]. Similarly a systematic review and meta-analysis carried out in 2014 from studies of low-, middleand high-income countries on 42,366 HIV patients showed a prevalence of depression ranging from $12.8 \%$ to $78 \%$ (there was no significant difference in the rate of depressive symptoms in HIV patients across low-, middleand high-income countries) and found that the likelihood of achieving good adherence was $42 \%$ lower in patient with depressive symptoms compared to those who were not [11]. However, a lower prevalence of major depressive disorder (8.1\%) was reported in a study carried out in HIV/AIDS patients in a semi-urban district in Uganda [17]. This difference in prevalences can be due to a number of factors such as differences in study methodology (use of patient self-reports versus structured diagnostic instruments or differences in study populations, semi-urban versus urban). A study carried out in Yaoundé, Cameroon, on newly diagnosed HIV-infected patients revealed that $63 \%$ of the study population had depressive symptoms [18]. Also, research carried out among HIV-infected patients on ART in a semi-urban centre in Cameroon reported that one in five participants met the lifetime criteria for major depression disorders [19].

Thus, this research aimed at providing data on the prevalence and determinants of depression and its association with adherence to ART among HIV/AIDS patients on HAART in the Southwest Regional Hospitals of Cameroon in 
view of ameliorating mental health interventions for patients living with HIV/AIDS in the Cameroon, as well as Africa as a whole, by establishing standard guidelines.

\section{METHODS}

\section{Study Design and Setting}

This was a cross-sectional, hospital-based study conducted at the Buea Regional Hospital (BRH) and Limbe Regional Hospital (LRH) in the Southwest Region of Cameroon, Fako division. The study was carried out for a 3-month period (16 October 2014 to 12 January 2015).

\section{Patients}

The study included HIV/AIDS patients on HAART at the Buea Regional and Limbe Regional Hospitals' day care centre during the study period. This included both male and female patients aged 21 years and above. We recruited 316 participants and eliminated 16 (12 with no CD4 counts, 4 withdrawals of consent). Participants were selected using a consecutive convenience sampling method. Patients present at the centres on days of study who were eligible and who consented were included in the study.

\section{Inclusion Criteria}

- HIV patients on HAART for at least the past 6 months with CD4 counts measured within the last 6 months.

- HIV patients aged 21 years and above.

- HIV patients who offered consent and signed the study consent form.

\section{Exclusion Criteria}

- Less than 6 months post-partum.

- Patients who had lost a loved one within the last 3 months because they are likely to present with post-traumatic depression.

- Acutely ill patients.

\section{Study Procedures}

\section{Data Collection}

We used consecutive convenience sampling until the desired sample size was reached. During routine clinic days, all potential study participants aged 21 years or older were approached and invited to participate in the study. The aim of the study, including the risks and benefits, was explained well in both the Pidgin and English languages to all the patients present. Patients indicating interest signed the consent form provided by the investigator while waiting for drug distribution and were then interviewed in private. A pre-designed and validated questionnaire was administered by the principal investigator to each participant. The questionnaire contained:

- Demographic data: age, sex, educational level, occupation, marital status and residence.

- The nine-item Patient Health Questionnaire (PHQ-9), a validated depression screening tool based on the Diagnostic and Statistical Manual of Mental Disorders, 4th Edition (DSM-IV) criteria [31]. A PHQ-9 score $\geq 10$ has a sensitivity of $88 \%$ and a specificity of $88 \%$ for major depression, which has led to its prominence in the primary care setting [20]. The advantages of the PHQ-9 questionnaire include that it is shorter than other depression rating scales, e.g., the Geriatric Depression Scale, which is a 15 -item questionnaire, can be administered in person by a clinician, by telephone or self-administered, facilitates diagnosis of major depression, provides assessment of symptom severity, is well validated and documented in a variety of populations and can be used in adolescents as young as 12 years of age [21]. However, the PHQ-9 is not without drawbacks as it is very limited in identifying depressed individuals with dysthymia (hence false negatives) [22].

- The Eight-Item Morisky Medication Adherence Scale, a well-known scale used to assess adherence to treatment in chronic diseases, 
was used to assess medication adherence. The scale assesses adherence with scores ranging from 0 to 8 .

- Questions assessing risk factors for depression.

- At the end of each day, the questionnaires were checked, validated and then stored for subsequent use for data entry.

\section{Statistical Analysis}

Data from the questionnaire were entered into Microsoft Excel 2010 and imported into Epi info for statistical analysis. Depression was based on the PHQ-9 scores, which range from 0 to 27. Depression was defined by a PHQ-9 score $\geq 5$ [23] and severity was characterised as none (0-4), mild (5-9), moderate (10-14), moderately severe (15-19) and severe $(\geq 20)$.

Adherence was defined as adherent (high) with a Morisky Medication Adherence Scale score of 0 and non-adherent (medium, low) with a score of $\geq 1$.

The study population was appropriately described according to age, gender, level of education, employment status and marital status using appropriate charts and frequency tables. Descriptive statistics were depicted using absolute numbers, percentages, ranges and means as appropriate.

The prevalence of depression was computed by univariate analysis and expressed as a percentage. Age, gender, employment status, marital status, level of education, family history of depression, alcohol consumption, smoking, living companion, funding source, CD4 count, duration from diagnosis of HIV infection, duration of treatment and HAART regimen were assessed for any significant association to depressive symptoms using the chi-square test and Fisher's exact test when appropriate. A $p$ value of $<0.05$ was considered statistically significant. Significant factors obtained from bivariate analysis were entered into a multivariate logistic regression model for control of potential confounders. Chi-square test was used to analyse significant associations between depression and non-adherence to HAART.

\section{Compliance with Ethics Guidelines}

All procedures performed in studies involving human participants were in accordance with the ethical standards of the institutional review board of the Faculty of Health Sciences, University of Buea-Cameroon, and with the Declaration of Helsinki of 1964, as revised in 2013, or comparable ethical standards. Informed consent was obtained from all patients for being included in this study.

\section{RESULTS}

\section{Socio-Demographic Characteristics of the Population}

Three hundred sixteen participants were recruited and 300 were retained. Of the 16 excluded, 12 did not have CD4 counts and 4 withdrew their consent. The ages of the study participants ranged from 22 to 74 years with a mean age of $40.9 \pm 9.7$ years. There were more participants between the ages of $31-40$ years (38.3\% of participants) compared to any other age group. Of the 300 study participants $80(26.7 \%)$ were males, most were employed, i.e. 234 (78.0\%), 140 (46.7\%) reported being married and most had primary as the maximum level of education, representing $52.7 \%$ (Table 1 ).

\section{Prevalence and Severity of Depressive Symptoms}

Of our 300 participants, 80 had depressive symptoms giving a prevalence of $26.7 \%$ (95\% CI $20.6-33.7 \%)$. Of the 80 participants with depression, $70(23.3 \%)$ had mild depression, 8 (2.7\%) had moderate depression, $2(0.7 \%)$ had moderately severe depression and none had severe depression (Table 2).

\section{Assessment of Factors Associated with Depression}

\section{Demographic Factors}

Of our 300 participants, the proportion of patients $\leq 40$ years with depression was 
Table 1 Sociodemographic and clinical characteristics of the study population $(N=300)$

\begin{tabular}{|c|c|c|}
\hline Variable & Frequency $(N=300)$ & Percentage (\%) \\
\hline \multicolumn{3}{|l|}{ Sex } \\
\hline Males & 80 & 26.7 \\
\hline Females & 220 & 73.3 \\
\hline \multicolumn{3}{|l|}{ Age (years) } \\
\hline $21-30$ & 44 & 14.7 \\
\hline $31-40$ & 115 & 38.3 \\
\hline $41-50$ & 95 & 31.7 \\
\hline $51-60$ & 37 & 12.3 \\
\hline $61-70$ & 6 & 2.0 \\
\hline $71-80$ & 3 & 1.0 \\
\hline \multicolumn{3}{|l|}{ Marital status } \\
\hline Married & 140 & 46.7 \\
\hline Widowed & 91 & 30.3 \\
\hline Single & 38 & 12.7 \\
\hline Divorce & 6 & 2 \\
\hline Cohabitate & 25 & 8.3 \\
\hline \multicolumn{3}{|c|}{ Educational status } \\
\hline None & 19 & 6.3 \\
\hline Primary & 158 & 52.7 \\
\hline Secondary & 68 & 22.7 \\
\hline High school & 30 & 10 \\
\hline University & 25 & 8.3 \\
\hline \multicolumn{3}{|c|}{ Occupational status } \\
\hline Employed & 234 & 78 \\
\hline Unemployed & 50 & 16.7 \\
\hline Retired & 16 & 5.3 \\
\hline \multicolumn{3}{|c|}{ Funding sources } \\
\hline Self & 196 & 65.3 \\
\hline Non-self & 104 & 34.7 \\
\hline \multicolumn{3}{|c|}{ Living companion } \\
\hline No & 56 & 18.7 \\
\hline Yes & 244 & 81.3 \\
\hline
\end{tabular}

Table 1 continued

\begin{tabular}{lll}
\hline Variable & Frequency $(N=300)$ & Percentage (\%)
\end{tabular}

Alcohol consumption

$\begin{array}{lrl}\text { No } & 280 & 93.3 \\ \text { Yes } & 20 & 6.7 \\ \text { Smoking } & & \\ \text { No } & 293 & 97.7 \\ \text { Yes } & 7 & 2.3\end{array}$

Duration from diagnosis of HIV infection (months)

$\begin{array}{lrl}\leq 23 & 79 & 26.3 \\ 24-59 & 110 & 36.7 \\ \geq 60 & 111 & 37\end{array}$

Duration on HAART treatment (months)

$\begin{array}{lrl}\leq 23 & 84 & 27.8 \\ 24-59 & 105 & 35.1 \\ \geq 60 & 111 & 37.1 \\ \mathrm{CD}_{4}^{+} & \text {count } & \text { cells/ } \mu \mathrm{l} \\ 0-50 & 5 & 1.7 \\ 51-200 & 18 & 5.7 \\ 201-350 & 95 & 31.8 \\ >350 & 182 & 60.8\end{array}$

ARV combinations

$\begin{array}{lll}\text { TLE } & 194 & 64.3\end{array}$

$\begin{array}{lll}\text { ZLN } & 69 & 23.0\end{array}$

$\begin{array}{lll}\text { TLLI } & 20 & 6.7\end{array}$

$\begin{array}{lll}\text { TLN } & 17 & 6.0\end{array}$

$T L E$ tenofovir, lamivudine, efavirenz; $Z L N$ zidovudine, lamivudine, nevirapine; $T L N$ tenofovir, lamivudine, nevirapine; $T L L I$ tenofovir, lamivudine, lopinavir, indinavir

significantly higher than those $>40$ years ( $p$ value $=0.02)$. Unmarried participants had a higher prevalence of depression (31.9\%) compared to married participants (20.7\%). This difference was statistically significant $(p$ value $=0.03)$. Employment status was also significantly associated with having depression 
Table 2 Severity of depression

\begin{tabular}{lcl}
\hline Depression severity & Frequency & Percentage \\
\hline Mild & 70 & 23.3 \\
Moderate & 8 & 2.7 \\
Moderately severe & 2 & 0.7 \\
Severe & 0 & 0 \\
Total & 80 & 26.7 \\
\hline
\end{tabular}

$(p$ value $=0.02)$. Other factors such as gender and educational status were not found to be significantly associated with depressive symptoms (Table 3).

\section{Social Factors}

Depression among participants who did not have a living companion (41.1\%) was higher than that among those living with someone $(23.4 \%)$. The difference was statistically significant $(p$ value $=0.01)($ Table 3$)$.

\section{Clinical factors}

Of the 300 participants, the prevalence of depression in participants with CD4 count $\leq 200$ cells $/ \mu$ l was significantly higher than that in participants with a CD4 count $>200$ cells $/ \mu \mathrm{l} \quad(52.2 \%$ vs. $24.9 \%, p$ value $=$ 0.01) (Table 4).

\section{Multivariate Analysis for Factors Associated with Depression}

In the multivariate analysis, we adjusted for factors associated with depression that had a $p$ value $<0.05$ in the bivariate analysis (age, marital status, employment status, living companion and CD4 count). After multivariate logistic regressions, age $\leq 40$, unemployment and CD4 count $\leq 200$ cells/ $\mu$ l were found to be independently associated with depressive symptoms (Table 5).

\section{Non-adherence}

Of our 300 participants 142 (47.3\%) were non-adherent as opposed to 158 (52.7\%) who were adherent to treatment.

\section{Adherence Pattern Among Patients with and without Depressive Symptoms}

Among the 80 participants with depressive symptoms, $75.0 \%$ were non-adherent to treatment as compared to $37.3 \%$ of those without depression. This difference was statistically significant ( $p$ value $<0.001$ ). For adherence pattern logistic regression, we adjusted for depression as a potential confounder. Running a logistic regression, those with depression were 5.04 times more likely to be non-adherent than those without depression (95\% CI 2.84-8.97, $p$ value $<0.001)$; hence, depressive symptoms were associated with non-adherence to HAART.

\section{DISCUSSION}

We carried out a cross-sectional study on HIV/ AIDS patients receiving antiretroviral therapy at the SW Regional Hospitals of an urban area in Cameroon. Our main objective was to determine the prevalence of depressive symptoms amongst HIV/AIDS patients on HAART, its determinants and its influence on adherence amongst patients accessing care in the treatment centres of the BRH and LRH. We recruited 300 participants of whom $73.3 \%$ were females. The mean duration on HAART was $47.6 \pm 36.8$ months with a minimum of 6 months.

The prevalence of depressive symptoms was $26.7 \%$ which was in accordance with that observed in the general population (the lower PHQ9 threshold was used, i.e. PHQ 9 score $\geq 5$ ). Prior studies have shown prevalence of depression among HIV-infected patients of $7 \%$ to $63 \%$ $[18,19]$. Such variations may be explained by the different instruments used to diagnose depression and by other methodological differences, such as the cut-off points used and differences in the study population. This high prevalence of depressive symptoms in our study population could be caused by psychological distress from chronic stress due to unemployment and the burden of care for the disease. Our result is similar to what was reported by a systematic review on depression assessment among persons with HIV in Sub-Saharan Africa 
Table 3 Demographic and social determinants of depression

\begin{tabular}{|c|c|c|c|c|}
\hline Characteristic & Total number $(n=300)$ & $\begin{array}{l}\text { Depression }(n=80) \\
\text { Frequency }(\%)\end{array}$ & $\begin{array}{l}\text { No Depression }(n=220) \\
\text { Frequency }(\%)\end{array}$ & $p$ value \\
\hline \multicolumn{5}{|l|}{ Gender } \\
\hline Male & 80 & $16(20.0)$ & $64(80.0)$ & \multirow[t]{2}{*}{0.12} \\
\hline Female & 220 & $64(29.1)$ & $156(70.9)$ & \\
\hline \multicolumn{5}{|l|}{ Age } \\
\hline$\leq 40$ & 159 & $51(32.1)$ & $108(67.9)$ & \multirow[t]{2}{*}{$0.02^{*}$} \\
\hline$>40$ & 141 & $29(20.6)$ & $112(79.4)$ & \\
\hline \multicolumn{5}{|l|}{ Marital status } \\
\hline Married & 140 & $29(20.7)$ & $111(79.3)$ & \multirow[t]{2}{*}{$0.03^{*}$} \\
\hline Unmarried & 160 & $51(31.9)$ & $109(68.1)$ & \\
\hline \multicolumn{5}{|c|}{ Educational level } \\
\hline No formal & 174 & $45(25.9)$ & $129(74.1)$ & \multirow[t]{2}{*}{0.71} \\
\hline Formal & 126 & $35(27.8)$ & $91(72.2)$ & \\
\hline \multicolumn{5}{|c|}{ Employment status } \\
\hline Employed & 234 & $55(23.5)$ & $179(76.5)$ & \multirow[t]{2}{*}{$0.02^{*}$} \\
\hline Unemployed & 66 & $25(37.9)$ & $41(62.1)$ & \\
\hline \multicolumn{5}{|c|}{ Financial supporter } \\
\hline Self & 196 & $55(28.1)$ & $141(71.9)$ & \multirow[t]{2}{*}{0.45} \\
\hline Non-self & 104 & $25(24.0)$ & $79(75.0)$ & \\
\hline \multicolumn{5}{|c|}{ Living companion } \\
\hline No & 56 & $23(41.1)$ & $33(58.9)$ & \multirow[t]{2}{*}{$0.01^{*}$} \\
\hline Yes & 244 & $57(23.4)$ & $187(76.6)$ & \\
\hline \multicolumn{5}{|c|}{ Alcohol consumption } \\
\hline No & 280 & $75(26.8)$ & $205(73.2)$ & \multirow[t]{2}{*}{0.86} \\
\hline Yes & 20 & $5(25.0)$ & $15(75.0)$ & \\
\hline \multicolumn{5}{|l|}{ Smoking } \\
\hline No & 293 & $77(26.3)$ & $216(73.7)$ & \multirow[t]{2}{*}{0.33} \\
\hline Yes & 7 & $3(42.9)$ & $4(57.1)$ & \\
\hline
\end{tabular}

* Statistically significant

by Tsai et al. in 2014, who found a $29.5 \%$ prevalence of probable depression [24]. These similarities could exist because both studies had similar study populations.
Our prevalence was higher than what was obtained in other studies: Tung et al. (19\%) and Olisah in Nigeria $(21.3 \%)$ and Joon in Korea (21\%) [25-27]. These differences could be due to the differences in the instruments used to 
Table 4 Clinical determinants of depression

\begin{tabular}{|c|c|c|c|c|}
\hline Characteristic & Total number $(n=300)$ & $\begin{array}{l}\text { Depression }(n=80) \\
\text { Frequency }(\%)\end{array}$ & $\begin{array}{l}\text { No depression }(n=220) \\
\text { Frequency }(\%)\end{array}$ & $p$ value \\
\hline \multicolumn{5}{|c|}{ Duration from diagnosis of HIV (months) } \\
\hline$<60$ & 188 & $48(25.5)$ & $140(74.5)$ & \multirow[t]{2}{*}{0.65} \\
\hline$\geq 60$ & 112 & $32(27.9)$ & $80(72.1)$ & \\
\hline \multicolumn{5}{|c|}{ Duration on treatment (months) } \\
\hline$<60$ & 189 & $49(25.9)$ & $140(74.1)$ & \multirow[t]{2}{*}{0.71} \\
\hline$\geq 60$ & 111 & $31(27.9)$ & $80(72.1)$ & \\
\hline \multicolumn{5}{|c|}{ CD4 count cells $/ \wedge 1$} \\
\hline$\leq 200$ & 23 & $11(52.2)$ & $12(47.8)$ & \multirow[t]{2}{*}{$0.01^{*}$} \\
\hline$>200$ & 277 & $69(24.9)$ & $208(75.1)$ & \\
\hline \multicolumn{5}{|c|}{ History of chronic illness } \\
\hline No & 297 & $80(26.9)$ & $217(73.1)$ & \multirow[t]{2}{*}{0.29} \\
\hline Yes & 3 & $0(0.0)$ & $3(100.0)$ & \\
\hline \multicolumn{5}{|c|}{ Family history of depression } \\
\hline No & 297 & $80(26.9)$ & $217(73.1)$ & \multirow[t]{2}{*}{0.29} \\
\hline Yes & 3 & $0(0.0)$ & $3(100.0)$ & \\
\hline \multicolumn{5}{|c|}{ HAART regimen } \\
\hline TLE & 194 & $53(27.8)$ & $141(72.2)$ & \multirow[t]{4}{*}{0.09} \\
\hline ZLN & 69 & $18(26.1)$ & $51(73.9)$ & \\
\hline TLLI & 20 & $6(30.0)$ & $14(70.0)$ & \\
\hline TLN & 17 & $3(17.7)$ & $14(82.3)$ & \\
\hline
\end{tabular}

* Statistically significant

diagnose depression, sample sizes and differences in the study population. The study carried out by Tung et al. had a smaller sample size and the HADS was used to screen for depression [25]. The use of PHQ-9 with a low cut-off $(\geq 5)$ in terms of severity of depression will discover an extra percentage of individuals with depressive symptoms as opposed to the HADS screening tool with a cut-off of HADS-D $\geq 8$ [23]. Olisah et al. studied adherence to highly active antiretroviral therapy in depressed patients with HIV/AIDS attending a Nigerian university teaching hospital clinic. The Centre for Epidemiological Studies Depression Scale (CES-D) was used to screen for depressive symptoms
[26]. Joon et al. used the Beck Depression Inventory and had a smaller sample size [27].

However, the prevalence in our study was lower than what was reported in other studies: L'akoa in Cameroon (63\%), Shittu in Nigeria $(56.7 \%)$, Nakimuli et al. in a systematic review in SSA $(31.2 \%)$ and Kitshoff in South Africa $(62 \%)$ [18, 28-30]. These differences could be due to differences in the tools used, sample size and the study population. The study by L'akoa et al. was on newly diagnosed HIV patients [18]. Shittu et al. in their study included both HIV patients on HAART and HAART-naïve patients [28]. Nakimuli et al. had a larger sample size from a group of studies over a 5-year period as 
Table 5 Multivariate analysis for factors associated with depression

\begin{tabular}{llll}
\hline Variable & Adjusted OR & $\mathbf{9 5 \%}$ CI & $\boldsymbol{p}$ value \\
\hline Marital status & & & \\
Married & Referent & & \\
Unmarried & 1.23 & $0.68-2.25$ & 0.49 \\
Age & & & \\
$>40$ & Referent & & \\
$\leq 40$ & 2.13 & $1.20-3.70$ & $0.01^{*}$ \\
Employment status & & \\
Employed & Referent & & \\
Unemployed & 2.38 & $1.26-4.50$ & $0.01^{*}$ \\
Living companion & & \\
Yes & Referent & & \\
No & 1.72 & $0.86-3.45$ & 0.12 \\
CD4 count cells/^1 & & \\
$>200$ & Referent & & \\
$\leq 200$ & 3.70 & $1.45-9.09$ & $0.01^{*}$ \\
\hline
\end{tabular}

* Statistically significant

well as differences in study design (systematic review vs. cross-sectional study) [31]. Kitshoff et al. also used the CES-D to screen for depressive symptoms [30].

This study showed that those who were unmarried had a higher prevalence of depressive symptoms. Unmarried people, especially the divorced and widowed, are much more likely to experience negative social determinants than those who are married because they carry the double stress of raising their children by themselves and work. This was similar to findings by Bhatia et al. [32]. In the study by Shittu et al., depressive symptoms were similar between married and unmarried patients [28].

In addition, unemployment was associated with depressive symptoms. This may be because economic instability leads to stress, frustration, dysfunctional family life and feelings of worthlessness. Joon in Korea [27] and Kitshoff in South Africa [30] also reported similar findings.

Also, those who did not have a living companion had a higher prevalence of depressive symptoms. This is in conformity with the literature, which says those who live alone are predisposed to developing depression [33]. This might be because loneliness predisposes them to feeling worthless and having poor appetites and concentration problems since they have no one to talk to and confide in. Tung in Malaysia did not find any significant association between having a living companion and depressive symptoms [25].

Our study showed that participants aged $\leq 40$ years had a higher prevalence of depressive symptoms. This is in line with the literature showing that most people experience depression between the ages of 20 and 40 [33]. This is the age at which most people settle down in life. The stigma associated with getting a job or psychological disturbance of not having a lifetime partner due to their HIV status might account for the increased depression rate. Other studies found no significant association between age and depressive symptoms [28].

Having a low CD4 count was associated with depressive symptoms. This might be due to the patients feeling discouraged and having loss of interest despite taking medication and still having a low CD 4 count level. L'akoa et al. reported similar findings from a study in Yaoundé [18].

The prevalence of depressive symptoms was higher in participants with a formal education, indicating that the level of education plays an important role in the prevalence of depression in patients. This might because those with a higher level of education have a better understanding of their illness and its symptoms. This is similar to findings in Canada [34] where respondents whose educational levels were less than secondary education had the lowest rate of depression and the highest prevalence rate of depression was seen among those with tertiary education. Our findings however contrast with findings by Shittu in Nigeria [35] and Kitshoff in South Africa [30].

Our study did not show a significant relationship between most clinical variables (duration from diagnosis of HIV infection, duration on HAART, type of HAART regimen) and depression. This is in line with findings in other studies: Joon et al. [27] and Tung et al. [25]. This 
indicates that these variables have no effect on the development of depression.

The non-adherence rate of all participants was $47.3 \%$; $75.0 \%$ of participants with depression were non-adherent to HAART compared to $37.3 \%$ of those without depression. The expression of depressive symptoms such as loss of interest, hopelessness, lack of energy and poor concentration seen in depressive disorders is likely to have contributed to non-adherence to HAART in the participants with depression. This is similar to the study by Olisah et al. on adherence to highly active antiretroviral therapy in depressed patients with HIV/AIDS attending a Nigerian university teaching hospital clinic where $63.6 \%$ of participants with depressive disorder had poor adherence to HAART [26]. These similarities could be due to the similarities in the sample sizes used. This prevalence is higher than that reported by Afiong in Nigeria (40.1\%) [36] and Samwel in Kenya (18\%) [4].

\section{Limitations}

- The study was hospital based and as such some patients with depressive disorders were unlikely to present to the hospital because of their depressed state.

- The results of our study do not allow the extension of such findings to a clinical condition of major depression, which requires a full clinical evaluation and presumably a specific treatment. Nonetheless, our results emphasise that clinicians should integrate the delivery of clinical care, targeted interventions and counselling against depressive symptoms through regular appointments to avoid poorer outcomes. These findings should stimulate clinicians to evaluate depression when the patient is not complying with the treatment.

- The use of self-report medication adherence to assess medication adherence (MMAS) was a limitation of this study. The patients might over-report non-adherence to HAART.

- Our study was cross-sectional and designed to determine the association of depression with non-adherence to HAART. As such, it could only determine whether there is an association between depression and non-adherence and not whether this association is a cause-effect relationship. With the latter aim, a prospective study is needed in which depressed patients are followed up to determine whether they are subsequently non-adherent to treatment.

- We could only assess the prevalence of depressive symptoms and not the prevalence of diagnosed depression because PHQ-9 is a screening tool that is mainly suggestive rather than diagnostic like other instruments used for depression diagnosis.

\section{CONCLUSION}

The prevalence of depressive symptoms is high (26.7\%) in HIV patients and depressive symptoms are associated with non-adherence to HAART. This implies that depressed HIV/AIDS patients tend not to follow up their treatment thereby increasing the possibility of complications and poor prognosis. Unemployment, being unmarried, age $\leq 40$ years, living alone and CD4 counts $\leq 200$ cells/ $\mu$ l were found to be factors associated with occurrence of depressive symptoms in HIV patients, with unemployment, age $\leq 40$ years and CD4 counts $\leq 200$ cells/ $\mu \mathrm{l}$ being independent factors. Many more female than male HIV patients tend to have depressive symptoms.

Thus, guidelines should be established for routine assessment (screening) of mental health, especially depressive symptoms of HIV patients, to improve the compliance with HAART and prognosis of the disease.

\section{ACKNOWLEDGEMENTS}

No funding or sponsorship was received for this study or publication of this article. All named authors meet the International Committee of Medical Journal Editors (ICMJE) criteria for authorship for this manuscript, take responsibility for the integrity of the work as a whole and have given final approval to the version to be published. 
Disclosures. Pleasure Atoh Ngum, Peter Nde Fon, Roland Cheofor Ngu, Vincent Siysi Verla and Henri Namme Luma have no potential conflicts of interest relevant to this article.

Compliance with Ethics Guidelines. All procedures performed in studies involving human participants were in accordance with the ethical standards of the institutional review board of the Faculty of Health Sciences, University of Buea-Cameroon, and with the Declaration of Helsinki of 1964, as revised in 2013, or comparable ethical standards. Informed consent was obtained from all patients for being included in this study.

Open Access. This article is distributed under the terms of the Creative Commons Attribution-NonCommercial 4.0 International License (http://creativecommons.org/licenses/ by-nc/4.0/), which permits any noncommercial use, distribution, and reproduction in any medium, provided you give appropriate credit to the original author(s) and the source, provide a link to the Creative Commons license, and indicate if changes were made.

\section{REFERENCES}

1. World Health Organization. HIV-AIDS and mental health. WHO 2008. (Internet). http://apps.who.int/ gb/archive/pdf_files/EB124/B124_6-en. Accessed 23 Feb 2017.

2. Fact sheet November 2016. UNAIDS (Internet). http://www.unaids.org/en/resources/fact-sheet. Accessed 23 Feb 2017.

3. UNAIDS. The Gap report. UNAIDS 2014. (Internet). http://www.unaids.org/en/resources/documents/ 2014/20140716_UNAIDS_gap_report. Accessed 23 Feb 2017.

4. WHO, Progress report 2011: global HIV/AIDS response (Internet). http://www.who.int/hiv/pub/ progress_report2011/en/. Accessed 20 Jan 2017.

5. WHO, HIV/AIDS (Internet). WHO. http://www. who.int/gho/hiv/en/. Accessed 23 Feb 2017.

6. UNAIDS. Global-AIDS-update. UNAIDS 2016. (Internet). http://www.unaids.org/sites/default/files/
media_asset/global-AIDS-update-2016_en. Accessed 24 Feb 2017.

7. The World Factbook-Central Intelligence Agency (Internet). https://www.cia.gov/library/ publications/the-world-factbook/fields/2155.html. Accessed 23 Feb 2017.

8. WHO, Suicide prevention (Internet). WHO. http:// www.who.int/mental_health/suicide-prevention/en/. Accessed 20 Jan 2017.

9. Saini S, Vijay Barar K. Impact of HIV associated neurocognitive disorders on activities of daily living and its association with depression in outdoor patients undergoing HAART. J Young Pharm. 2016;8:279-83.

10. Mathers CD, Loncar D. Projections of global mortality and burden of disease from 2002 to 2030. PLoS Med. 2006;3:e442.

11. Uthman OA, Magidson JF, Safren SA, Nachega JB. Depression and adherence to antiretroviral therapy in low-, middle- and high-income countries: a systematic review and meta-analysis. Curr HIV/AIDS Rep. 2014;11:291-307.

12. National Institute of Mental Health. depression_and_hiv. (Internet). Bethesda(MD): National institute of Mental Health, National Institutes of Health, US Department of Health and Human services. 2002. http://www.nimh.nih.gov/publicat/ index.cfm. Accessed 23 Feb 2017.

13. Chaudhury S, Bakhla AK, Saini R. Prevalence, impact, and management of depression and anxiety in patients with HIV: a review (Internet). Neurobehav HIV Med. 2016. https://www.dovepress. $\mathrm{com} /$ nhiv-and-management-of-depression-andanxiety-in-patients-peer-reviewed-fulltext-articleNBHIV. Accessed 23 Feb 2017.

14. Tegger MK, Crane HM, Tapia KA, Uldall KK, Holte SE, Kitahata MM. The effect of mental illness, substance use, and treatment for depression on the initiation of highly active antiretroviral therapy among HIV-infected individuals. AIDS Patient Care STDs. 2008;22:233-43.

15. Abas M, Ali G-C, Nakimuli-Mpungu E, Chibanda D. Depression in people living with HIV in sub-Saharan Africa: time to act. Trop Med Int Health. 2014;19:1392-6.

16. Nyirenda M, Chatterji S, Rochat T, Mutevedzi P, Newell M-L. Prevalence and correlates of depression among HIV-infected and -affected older people in rural South Africa. J Affect Disord. 2013;151:31-8.

17. Kinyanda E, Hoskins S, Nakku J, Nawaz S, Patel V. Prevalence and risk factors of major depressive 
disorder in HIV/AIDS as seen in semi-urban Entebbe district, Uganda. BMC Psychiatry. 2011;11:205.

18. L'akoa RM, Noubiap JJN, Fang Y, Ntone FE, Kuaban C. Prevalence and correlates of depressive symptoms in HIV-positive patients: a cross-sectional study among newly diagnosed patients in Yaoundé, Cameroon. BMC Psychiatry. 2013;13:228.

19. Gaynes BN, Pence BW, Atashili J, O’Donnell J, Kats $D$, Ndumbe PM. Prevalence and predictors of major depression in hiv-infected patients on antiretroviral therapy in Bamenda, a semi-urban center in Cameroon. Chêne G, editor. PLoS One. 2012;7:e41699.

20. Kroenke K, Spitzer RL, Williams JB. The PHQ-9: validity of a brief depression severity measure. J Gen Intern Med. 2001;16:606-13.

21. PHQ-9 Depression Scale, University of Washington AIMS Center (Internet). https://aims.uw.edu/ resource-library/phq-9-depression-scale. Accessed 22 Feb 2017.

22. Eack SM, Greeno CG, Lee B-J. Limitations of the patient health questionnaire in identifying anxiety and depression: many cases are undetected. Res Soc Work Pract. 2006;16:625-31.

23. Hansson M, Chotai J, Nordstöm A, Bodlund O. Comparison of two self-rating scales to detect depression: HADS and PHQ-9. Br J Gen Pract J R Coll Gen Pract. 2009;59:e283-8.

24. Tsai AC. Reliability and validity of depression assessment among persons with HIV in sub-Saharan Africa: systematic review and meta-analysis. J Acquir Immune Defic Syndr. 1999;2014(66):503-11.

25. Yee TM, Gee MLH, Guan NC, Jin JT. Identifying depression among the human immunodeficiency virus (HIV) patients in University Malaya Medical Centre, Kuala Lumpur, Malaysia. 2009. https://pdfs. semanticscholar.org/1e87/9320044def26c84b350ee f49c91e35c51870.pdf. Accessed 21 Jan 2017.

26. Olisah VO, Baiyewu O, Sheikh TL. Adherence to highly active antiretroviral therapy in depressed patients with HIV/AIDS attending a Nigerian university teaching hospital clinic. Afr J Psychiatry. 2010;13:275-9.
27. Song JY, Lee JS, Seo YB, Kim IS, Noh JY, Baek JH, et al. Depression among HIV-infected patients in Korea: assessment of clinical significance and risk factors. Infect Chemother. 2013;45:211-6.

28. Ro S, Ba I, Gt O, Ao M, Lo O, Ak S, et al. Prevalence and correlates of depressive disorders among people living with HIV/AIDS, in North Central Nigeria. J AIDS Clin Res. 2013;4(11):1-7.

29. Hoffmann C, Kamps BS. HIV medicine. Paris: Flying Publisher; 2007.

30. Kitshoff C, Naidoo SS. The association between depression and adherence to antiretroviral therapy in HIV-positive patients, KwaZulu-Natal, South Africa. S Afr Fam Pract (Internet). 2012;54. http:// www.ajol.info/index.php/safp/article/view/76200. Accessed 21 Jan 2017.

31. Nakimuli-Mpungu E, Bass JK, Alexandre P, Mills EJ, Musisi S, Ram M, et al. Depression, alcohol use and adherence to antiretroviral therapy in sub-Saharan Africa: a systematic review. AIDS Behav. 2012;16:2101-18.

32. Bhatia MS, Munjal S. Prevalence of depression in people living with HIV/AIDS undergoing ART and factors associated with it. J Clin Diagn Res JCDR. 2014;8:WC01-4.

33. Haggerty $\mathrm{J}$, read $\mathrm{MD} \sim 2$ min. Risk factors for depression (Internet). Psych Cent. 2016. https:// psychcentral.com/lib/risk-factors-for-depression/. Accessed 21 Jan 2017.

34. Offord DR, Boyle MH, Campbell D, Goering P, Lin $\mathrm{E}$, Wong $\mathrm{M}$, et al. One-year prevalence of psychiatric disorder in Ontarians 15 to 64 years of age. Can J Psychiatry Rev Can Psychiatr. 1996;41:559-63.

35. WHO. Adherence to long-term therapies: evidence for action (Internet). WHO. http://www.who.int/ chp/knowledge/publications/adherence_report/en/. Accessed 20 Jan 2017.

36. Oku AO, Owoaje ET, Ige OK, Oyo-ita A. Prevalence and determinants of adherence to HAART amongst PLHIV in a tertiary health facility in south-south Nigeria. BMC Infect Dis. 2013;13:401. 